\title{
Evaluation of biochemical parameter in polycystic ovarian disease patients attending tertiary care hospital
}

\author{
Aditi Saha ${ }^{1}$, Anirban Das Gupta ${ }^{2 *}$ \\ ${ }^{1}$ Department of Biochemistry, ${ }^{2}$ Department of Anatomy, Konaseema Institute of Medical Science, Amalapuram, Andhra \\ Pradesh, India
}

Received: 09 December 2021

Accepted: 05 January 2022

\section{*Correspondence:}

Dr. Anirban Das Gupta,

E-mail: dr.anirbanbsmc@gmail.com

Copyright: ( $)$ the author(s), publisher and licensee Medip Academy. This is an open-access article distributed under the terms of the Creative Commons Attribution Non-Commercial License, which permits unrestricted non-commercial use, distribution, and reproduction in any medium, provided the original work is properly cited.

\begin{abstract}
Background: PCOS might be a complex multigenic disorder with strong epigenetic and environmental influences, such as diet and other lifestyle factors. It is associated with abdominal adiposity, insulin resistance, obesity, metabolic disorders and cardiovascular risk factors. Based on literature search and non-uniformity in the finding of various author present study has been designed to evaluate the biochemical parameter in polycystic ovarian disease patients attending tertiary care hospital.

Methods: The study population include 50 untreated patients diagnosed to be polycystic ovarian disease. Parameters like age, BMI (body mass index), fasting plasma glucose, lipid profile overnight fasting plasma insulin, dehydroepiandrosterne sulphate, $(\mu \mathrm{g} / \mathrm{dl})$ (DHEAS), LH, FSH, LH/FSH ratio, HOMA IR (homeostasis model assessment of insulin resistance) and quantitative insulin sensitivity check index (QUICKI) and fasting serum plasma glucose to insulin ratio was measured in both group of patients.

Results: The mean value of glucose insulin ratio was $4.88 \pm 1.911$ in PCOD group and $8.74 \pm 4.61$ in control group, the $\mathrm{p}$ value was 0.004909 . The mean of $\mathrm{LH} / \mathrm{FSH}$ ratio was $1.93 \pm 0.42$ in PCOD group and $1.03 \pm 0.199$ in control group. The $\mathrm{p}$ value was $<0.05$. The mean of HOMA IR was $7.87 \pm 0.87$ in PCOD group and $2.036 \pm 0.26$ in control group, with $\mathrm{p}$ value 0.00001 .

Conclusions: From present study we can conclude that the mean age was $22.05 \pm 4.649$ years and the mean BMI was $27.32 \pm 6$. Hyperglycemia and dyslipidemia were common in PCOD patients. The mean of HOMA IR was significantly higher and the mean value of QUICKI was significantly lower in PCOD group.
\end{abstract}

Keywords: HOMA IR, LH/FSH, PCOD, QUICKI

\section{INTRODUCTION}

Stein et al in 1935 published his cases series finding of seven cases and concluded that patients were presented with amenorrhoea and bilateral polycystic ovaries which was result of hormonal influences. It was not responded to estrogen and was successfully treated with wedge resection without recurrence. ${ }^{1}$ After around one century since publication of this paper and with the development in radiological and biochemical diagnostics, pathogenesis of polycystic ovarian diseases is still controversial. PCOS might be a complex multigenic disorder with strong epigenetic and environmental influences, such as diet and other lifestyle factors. It is associated with abdominal adiposity, insulin resistance, obesity, metabolic disorders and cardiovascular risk factors. ${ }^{2}$ Rotterdam criteria is used for definition and diagnosis of PCOS which include all combination of evidence of hyperandrogenism, evidence of oligoanovulation, and PCOM. ${ }^{3}$ In addition to dysregulation of steroidogenesis, granulosa cell dysfunction and disordered folliculogenesis, PCOS is also associated with metabolic syndrome. ${ }^{4}$ after going through various literature we have observed that there is variability in the conclusion of various author regarding changes biochemical parameters associated with PCOS. Najem et al from his study has concluded that more than half were 
obese, and the prevalence of diabetes, hypertension and thyroid disease in our patients seemed to be underestimated in comparison to other parts of the world. ${ }^{5}$ Swetha et al has reported that PCOS women had higher BMI, significantly increased total cholesterol, triglycerides, LDL-C and VLDL-C. On the other hand, serum levels of HDL-C were significantly lower in this group compared to controls. ${ }^{6}$ The findings of this study confirm the association between BMI and dyslipidaemia in PCOS. But Chae et al from Korea reported that women with PCOS without HA are common in Korea and are less likely to have metabolic dysfunction, insulin resistance and elevated BP. ${ }^{7}$

Based on literature search and non-uniformity in the finding of various author present study has been designed to evaluate the biochemical parameter in polycystic ovarian disease patients attending tertiary care hospital.

\section{METHODS}

This was a prospective randomized observational case control study conducted in the department of biochemistry Konaseema institute of medical science Amalapuram from July 2015 to May 2018.

\section{Study population}

The study population included 50 untreated patients who were attending the infertility clinic in outpatient department of obstetrics with infertility and diagnosed to be polycystic ovarian disease were enrolled randomly based on inclusion and exclusion criteria. Similarly 50 healthy female without any symptom and normal ovarian USG were enrolled as control.

\section{Inclusion criteria}

Age 20 to 35 years. Diagnosed cases of PCOS based on Rotterdam's criteria.

\section{Exclusion criteria}

Endocrinological disorder like diabetes mellitus, thyroid disorder. Hepatic and kidney disease. Malignancy.

\section{Ethics}

This study was approved by institutional ethics committee. A written informed consent was taken from women before enrolment into this study

\section{Method}

A standard predesigned form was used to take the medical history of all the patients for uniformity. For the diagnosis of PCOS Rotterdam's criteria was used. ${ }^{4}$ Women diagnosed with infertility were randomly selected for this study and divided into two groups. Similarly 50 healthy female without any symptom and normal ovarian USG were enrolled as control.

Parameters like age, BMI (body mass index), fasting plasma glucose, lipid profile overnight fasting plasma insulin, dehydroepiandrosterne sulphate, $(\mu \mathrm{g} / \mathrm{dl})$ (DHEAS), LH, FSH, LH/FSH ratio, HOMA IR (homeostasis model assessment of insulin resistance) and quantitative insulin sensitivity check index (QUICKI) and fasting serum plasma glucose to insulin ratio was measured in both group of patients. HOMA IR was calculated by formula fasting insulin $(\mathrm{mIU} / \mathrm{ml} \times$ fasting glucose $(\mathrm{mg} / \mathrm{dl}) / 405 .{ }^{8}$ Insulin sensitivity QUICKI was calculated by formulae $(1 / \log$ insulin $+1 / \log$ glucose $){ }^{9}$ For estimation of other parameters COBASE 411 immunochemistry analyser was used. Blood sample were collected during the follicular phase between the second and the fourth day of menstrual cycle for LH and FSH.

\section{Statistical analysis}

Data obtained was entered into SPSS 16.0 software and data was analysed by unpaired t-test $\mathrm{p}$ value less than 0.05 was considered statistically significant.

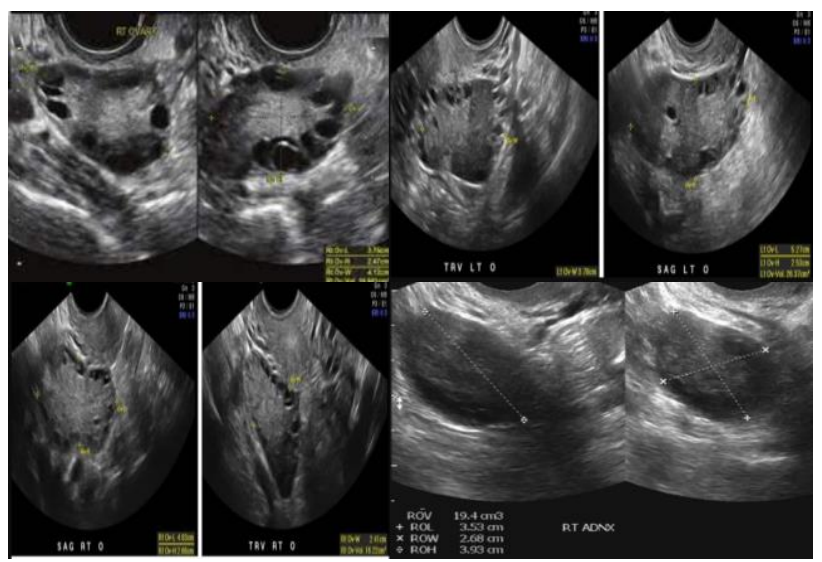

Figure 1: USG finding of patients with PCOS.

\section{RESULTS}

As per selection criteria 50 patients diagnosed as polycystic ovarian disease and 50 healthy controls were enrolled for this study as per selection criteria.

Table 1: Demographic profile of patients and control.

\begin{tabular}{|c|c|c|c|}
\hline Variables & Patients & Control & $\begin{array}{l}\mathbf{P} \\
\text { value }\end{array}$ \\
\hline Age (years) & $22.36 \pm 5.89$ & $23.52 \pm 6.027$ & 0.25 \\
\hline Marital Married & 22 & 20 & \multirow{2}{*}{0.68} \\
\hline status Unmarried & 28 & 30 & \\
\hline BMI $\left(\mathrm{Kg} / \mathrm{m}^{2}\right)$ & $25.36 \pm 2.24$ & $21.83 \pm 1.75$ & 0.000 \\
\hline SBP (mm of $\mathbf{H g})$ & $123.75 \pm 8.24$ & $116.4 \pm 7.87$ & 0.003 \\
\hline DBP (mm of Hg) & $116.4 \pm 7.87$ & $79.20 \pm 1.89$ & 0.02 \\
\hline
\end{tabular}


Mean age of patients with PCOD was $22.36 \pm 5.89$ years and in control group it was 23.52 \pm 6.027 ( $\mathrm{p}$ value $=0.25$ ). Both group were comparable to each other regarding marital status.

BMI was significantly higher in PCOD group then control $(25.36 \pm 2.24$ versus $21.83 \pm 1.75)$ the $p$ value was less than 0.05. The SBP (123.75 \pm 8.24 versus $116.4 \pm 7.87)$ and DBP (116.4 \pm 7.87 versus $79.20 \pm 1.89)$ was significantly higher in PCOD group than control.

Regarding metabolic profile of patients, fasting plasma glucose (FPG) was significantly higher in PCOD group then control $(116.61 \pm 10.79$ versus 89.6 \pm 4.90$)$. Postprandial plasma glucose (PPPG) was significantly higher in PCOD group then control $(180.21 \pm 24.25$ versus $132.54 \pm 12.32$ ).

Table 2: Metabolic profile of patients and control.

\begin{tabular}{|llll|}
\hline Variables & Patients & Control & P value \\
\hline FPG (mg/dl) & $116.61 \pm 10.79$ & $89.6 \pm 4.90$ & 0.0001 \\
\hline $\begin{array}{l}\text { PPPG } \\
\text { (mg/dl) }\end{array}$ & $180.21 \pm 24.25$ & $132.54 \pm 12.32$ & 0.00001 \\
\hline $\begin{array}{l}\text { Total chol. } \\
\text { (mg/dl) }\end{array}$ & $210.21 \pm 14.121$ & $174.32 \pm 9.47$ & 0.002 \\
\hline LDL (mg/dl) & $172.12 \pm 8.97$ & $134.25 \pm 14.22$ & 0.0001 \\
\hline HDL (mg/dl) & $37.51 \pm 1.24$ & $40.46 \pm 2.13$ & 0.003 \\
\hline TG (mg/dl) & $191.57 \pm 12.26$ & $145.36 \pm 14.3$ & 0.0002 \\
\hline
\end{tabular}

Regarding lipid profile total cholesterol was significantly higher in PCOD group than control (210.21 \pm 14.121 versus $174.32 \pm 9.47) \mathrm{p}$ value was 0.002 . LDL cholesterol was significantly higher in PCOD group than control (172.12 \pm 8.97 versus $134.25 \pm 14.22) \mathrm{p}$ value was 0.0001 . HDL cholesterol was significantly lower in PCOD group than control $(37.51 \pm 1.24$ versus $40.46 \pm 2.13) \mathrm{p}$ value was 0.003 . Triglyceride concentration was significantly higher in PCOD group than control $(191.57 \pm 12.26$ versus $145.36 \pm 14.3) \mathrm{p}$ value was 0.0001

Table 3: Hormonal profile of patients and control.

\begin{tabular}{|llll|}
\hline Variables & Patients & Control & P value \\
\hline $\begin{array}{l}\text { LH } \\
(\mathbf{m I U} / \mathrm{ml})\end{array}$ & $10.84 \pm 0.62$ & $6.06 \pm 1.2$ & 0.00001 \\
\hline $\begin{array}{l}\text { FSH } \\
(\mathbf{m I U} / \mathrm{ml})\end{array}$ & $5.94 \pm 0.89$ & $5.94 \pm 0.89$ & 0.27 \\
\hline FPI & $25.9 \pm 1.41$ & $11.9 \pm 1.9$ & 0.0001 \\
\hline $\begin{array}{l}\text { Glucose/ } \\
\text { insulin } \\
\text { ratio }\end{array}$ & $4.88 \pm 1.911$ & $8.74 \pm 4.61$ & 0.004 \\
\hline LH/FSH & $1.93 \pm 0.42$ & $1.03 \pm 0.199$ & 0.00023 \\
\hline HOMA IR & $7.87 \pm 0.87$ & $2.036 \pm 0.26$ & 0.0001 \\
\hline QUICKI & $0.2915 \pm 0.00021$ & $0.354 \pm 0.84$ & 0.0001 \\
\hline $\begin{array}{l}\text { DHEAS } \\
(\boldsymbol{\mu g} / \mathbf{d l})\end{array}$ & $284.69 \pm 48.35$ & $198.88 \pm 56.24$ & 0.0001 \\
\hline
\end{tabular}

Regarding comparison of hormonal profile of patients and control, serum LH mean value in PCOD group was $10.84 \pm 0.62 \mathrm{mIU} / \mathrm{ml}$ and $6.06 \pm 1.2 \mathrm{mIU} / \mathrm{ml}$ in control with $\mathrm{p}$ value $<0.00001$. Mean FSH level was $5.94 \pm 0.89 \mathrm{mIU} / \mathrm{ml}$ in control group and $5.94 \pm 0.89 \mathrm{mIU} / \mathrm{ml}$ in PCOD group with $\mathrm{p}$ value 0.27 . The fasting plasma insulin was $25.9 \pm 1.41 \mathrm{mIU} / \mathrm{l}$ in PCOD group and $11.9 \pm 1.9 \mathrm{mIU} / \mathrm{l}$ in control group B with p value 0.0001 .

The mean value of glucose insulin ratio was $4.88 \pm 1.911$ in PCOD group and $8.74 \pm 4.61$ in control group, the $\mathrm{p}$ value was 0.004909 . The mean of $\mathrm{LH} / \mathrm{FSH}$ ratio was $1.93 \pm 0.42$ in PCOD group and $1.03 \pm 0.199$ in control group. The $p$ value was $<0.05$. The mean of HOMA IR was $7.87 \pm 0.87$ in PCOD group and $2.036 \pm 0.26$ in control group, with $\mathrm{p}$ value 0.00001 . The mean value of QUICKI was $0.2915 \pm 0.00021$ in PCOD group and $0.354 \pm 0.84$ in control group with $\mathrm{p}$ value 0.00001 . Mean serum DHEAS level was $284.69 \pm 48.35 \mu \mathrm{g} / \mathrm{dl}$ in patient with PCOS and $198.88 \pm 56.24 \mu \mathrm{g} / \mathrm{dl}$ in patients without PCOS. The $\mathrm{p}$ value was 0.0001 .

\section{DISCUSSION}

In present study we have evaluated biochemical parameters of 50 patients with polycystic ovarian disease in comparison to healthy control. Mean age of patients with PCOD was $22.36 \pm 5.89$ years. Ramanand et al has reported that the mean age was $22.05 \pm 4.649$ years and the mean BMI was 27.32 \pm 6 . This finding supports our study. ${ }^{10}$ BMI was significantly higher in PCOD group then control $(25.36 \pm 2.24$ versus $21.83 \pm 1.75)$. This finding is supported by the work of Wang et al and Beydoun et al. ${ }^{11,12}$ BentleyLewis et al has report pregnant women with PCOS have a greater risk of perinatal morbidity from pregnancyinduced hypertension (PIH) and preeclampsia (PE) than non-PCOS pregnancies as demonstrated in a meta-analysis of pregnancy outcomes in women with PCOS compared to controls, this statement corroborates with our study. ${ }^{13}$

Regarding metabolic profile of patients with PCOD, the fasting and postprandial was significantly higher in PCOD group than control and total cholesterol LDL and triglyceride was significantly higher and HDL was significantly lower in PCOD group than control. Kiranmayee et al showed different types of dyslipidemia are probably the net result of interfering influences of hyperandrogenism, insulin resistance, environmental factors and genetics this finding supports our study. ${ }^{14}$ Kheirollahi et al has reported that TyG, TG/HDL-C, and TC/HDL-C indices might be good indicators of IR among Iranian women diagnosed with PCOS this corroborates with our study. ${ }^{15}$

Regarding hormonal profile of patients the mean of $\mathrm{LH} / \mathrm{FSH}$ ratio was $1.93 \pm 0.42$ in PCOD group and $1.03 \pm 0.199$ in control group. The mean of HOMA IR was significantly higher and the mean value of QUICKI was significantly lower in PCOD group. Mean serum DHEAS level was $284.69 \pm 48.35 \mu \mathrm{g} / \mathrm{dl}$ in patient with PCOS and 
$198.88 \pm 56.24 \mu \mathrm{g} / \mathrm{dl}$ in patients without PCOS. This finding was significant statistically. Nahar et al reported that more than half of cases had $\mathrm{LH} / \mathrm{FSH}$ ratio $>2$. Positive correlation was found among increased BMI, increased $\mathrm{LH} / \mathrm{FSH}$ ratio, serum testosterone, serum $\mathrm{TSH}$, fasting blood sugar, fasting insulin and insulin resistance this finding corroborates with our study. ${ }^{16}$

Tosi et al has demonstrated that insulin resistance, as assessed by the glucose clamp technique, is a very common feature in women with PCOS, even in normalweight subjects this finding supports our study. ${ }^{17}$ Goodarzi et al has reported that substantial heritabilities of APAs, particularly DHEAS, have been found in the general population and in women with PCOS that supports our study. ${ }^{18}$

Moran et al has reported that The $\mathrm{A}_{4}$ and DHEAS levels were significantly higher in non-obese than in obese PCOS patients. A significant correlation between $\mathrm{LH}$ and $\mathrm{A}_{4}$ in nonobese PCOS patients was observed. ${ }^{19}$ Smitha et al has reported that the mean DHEAS concentration was higher in PCOS group this finding support our study. ${ }^{20}$

\section{CONCLUSION}

From present study we can conclude that the mean age was $22.05 \pm 4.649$ years and the mean BMI was $27.32 \pm 6$. Hyperglycemia and dyslipidemia is common in PCOD patients. The mean of HOMA IR was significantly higher and the mean value of QUICKI was significantly lower in PCOD group. LH/FSH ratio and DHEAS was significantly higher. So PCOD is associated with insulin resistance and increased DHEAS.

\section{Funding: No funding sources}

Conflict of interest: None declared

Ethical approval: The study was approved by the Institutional Ethics Committee

\section{REFERENCES}

1. Stein IF, Leventhal ML. Amenorrhea associated with bilateral polycystic ovaries. Am J Obstet Gynecol. 1935;29:181-91.

2. Escobar-Morreale HF. Polycystic ovary syndrome: definition, aetiology, diagnosis and treatment. Nat Rev Endocrinol. 2018;14(5):270-84.

3. Rosenfield RL, Ehrmann DA. The pathogenesis of polycystic ovary syndrome (PCOS): the hypothesis of PCOS as functional ovarian hyperandrogenism revisited. Endocr Rev. 2016;37(5):467-520.

4. Rotterdam ESHRE/ASRM-Sponsored PCOS Consensus Workshop Group. Revised 2003 consensus on diagnostic criteria and long-term health risks related to polycystic ovary syndrome. Fertil Steril. 2004;81:19-25.

5. Najem F, Elmehdawi R, Swalem A. Clinical and biochemical characteristics of polycystic ovary syndrome in Benghazi- Libya; a retrospective study. Libyan J Med. 2008;3(2):71-4.

6. Swetha N, Vyshnavi R, Modagan P, Rajagopalan B. A correlative study of biochemical parameters in polycystic ovarian syndrome. Int J Biol Med Res. 2013;4(2):3148-54

7. Chae SJ, Kim JJ, Choi YM, Hwang KR, Jee BC, Ku $\mathrm{SY}$, et al. Clinical and biochemical characteristics of polycystic ovary syndrome in Korean women. Hum Reprod. 2008;23(8):1924-31.

8. Matthews DR, Hosker JP, Rudenski AS, Naylor BA, Treacher DF, Turner RC. Homeostasis model assessment: insulin resistance and beta-cell function from fasting plasma glucose and insulin concentrations in man. Diabetologia. 1985;28(7):4129.

9. Katz A, Nambi SS, Mather K, Baron AD, Follmann DA, Su. Quantitative insulin sensitivity check index: a Sullivan Gple, accurate method for assessing insulin sensitivity in humans. J Clin Endocrinol Metab. 2000;85(7):2402-10.

10. Ramanand SJ, Ghongane BB, Ramanand JB, Patwardhan MH, Ghanghas RR, Jain SS. Clinical characteristics of polycystic ovary syndrome in Indian women. Indian J Endocrinol Metab. 2013;17(1):13845.

11. Wang F, Dai W, Yang XH, Guo YH, Sun YP. Analyses of optimal body mass index for infertile patients with either polycystic or non-polycystic ovary syndrome during assisted reproductive treatment in China. Scient Rep. 2016;6(1):1-9.

12. Beydoun HA, Stadtmauer L, Beydoun MA, Russell H, Zhao Y, Oehninger S. Polycystic ovary syndrome, body mass index and outcomes of assisted reproductive technologies. Reprod Biomed Online. 2009;18(6):856-63.

13. Bentley-Lewis R, Seely E, Dunaif A. Ovarian hypertension: polycystic ovary syndrome. Endocrinol Metab Clin North Am. 2011;40(2):433-49,ix-x.

14. Kiranmayee D, Kavya K, Himabindu Y, Sriharibabu M, Madhuri GLJ, Venu S. Correlations between anthropometry and lipid profile in women with PCOS. J Hum Reprod Sci. 2017;10(3):167-72.

15. Kheirollahi A, Teimouri M, Karimi M, Vatannejad A, Moradi N, Borumandnia N, et al. Evaluation of lipid ratios and triglyceride-glucose index as risk markers of insulin resistance in Iranian polycystic ovary syndrome women. Lipids Health Dis. 2020;19(1):1-9.

16. Nahar K, Mahfuza G, Begum SA, Khatun K, Islam MR. Clinical, biochemical and hormonal profile of polycystic ovary syndrome. J Nat Inst Neurosci Bangladesh. 2017;3(2):94-8.

17. Tosi F, Bonora E, Moghetti P. Insulin resistance in a large cohort of women with polycystic ovary syndrome: a comparison between euglycaemichyperinsulinaemic clamp and surrogate indexes. Hum Reprod. 2017;32(12):2515-21.

18. Goodarzi MO, Carmina E, Azziz R. DHEA, DHEAS and PCOS. J Steroid Biochem Mol Biol. 2015;145:213-25. 
19. Moran C, Arriaga M, Arechavaleta-Velasco F, Moran $\mathrm{S}$. Adrenal androgen excess and body mass index in polycystic ovary syndrome. J Clin Endocrinol Metab. 2015;100(3):942-50.

20. Smitha M, Jyothi S, Acharya A. A prospective study of insulin resistance among infertile women with polycystic ovarian syndrome. Int J Reprod Contracept Obstet Gynecol. 2018;7:3786-9.
Cite this article as: Saha A, Gupta AD. Evaluation of biochemical parameter in polycystic ovarian disease patients attending tertiary care hospital. Int $\mathbf{J}$ Reprod Contracept Obstet Gynecol 2022;11:496-500. 